\title{
Assessing the Demand Factors for Residential Earthquake Insurance in Taiwan: Empirical Evidence on Spatial Econometrics
}

\author{
Li-Hua Lai \\ National Kaohsiung First University of Science and Technology \\ E-Mail: lihua@ccms.nkfust.edu.tw \\ Hsiu-Yi Hsieh \\ National Kaohsiung First University of Science and Technology \\ Jin Wen Institute of Technology \\ E-Mail: Yiz18@jwit.edu.tw
}

\begin{abstract}
The residential earthquake insurance of 2002 created additional protected residential earthquake insurance plan, under which residential earthquake insurance is available to individuals from insurance industry in Taiwan. Earthquake damages that occurrence in Taiwan remain largely uninsured losses despite the efforts of governmental and private insurance programs. Spatial Econometrics has been recognized as one of the top key issues in residential earthquake insurance demand field. The demand factors for residential earthquake insurance have been proved to be either directly or indirectly related to many interdependent environment variables, such as disposal income, government subsidized and region. Previous researches only focused on individual's behavior issues, no different spatial research framework has been proposed before. This paper applies spatial econometrics theory together with spatial autocorrelation and panel regression models to investigate the relationship between insurance demand and disposal income, government subsidized, area/spatial in Taiwan's conditions during the period 2002 through 2004. The results of this paper indicate that government subsidized loan is significantly negative relationship with demand for residential earthquake insurance, which was to the contrary of the hypothesis. Disposal income and spatial variables are significantly positive relationship with demand for residential earthquake insurance, which was to the accord with the hypothesis. Although region has significant effects on
\end{abstract}


the demand for residential earthquake insurance in Taiwan, the more improving the ability of explanations can be contributed by the spatial effect model if spatial variable is linked with demand for residential earthquake insurance.

Keywords: Taiwan Residential Earthquake Insurance Pool (TREIP), Spatial Econometrics

\section{INTRODUCTION}

Earthquake risk potentially can bring economic catastrophe to large geographical regions (SIGMA, 2001). The earthquake presents an important threat to humans and property in earthquake prone areas like Taiwan where situated at the junction of the Eurasian Plate and the Philippine Sea Plate, is a high-risk seismic belt and suffers considerable earthquake damage. Despite the catastrophic loss potential, the exposure to loss and financial impact tend to be localized to specific areas or regions in Taiwan. During the 1999 Chi-Chi 921 earthquake, these were resulted in about 2500 deaths, 11,000 injuries, and more than 100 thousand households suffered damage in the whole area of Taiwan. This issue of locality also has a psychological dimension. Property owners outside the affected area may not wish to subsidize those property owners with interests in the affected area. This feature impacts the structure of insurance markets for this type of risk. The public sector also may become involved in financing catastrophic loss events. Since then, the central government of Taiwan has devoted efforts on emergency funding to deal with the immediate financial problems associated with catastrophic events, and provides disaster support to minimize loss of life and property damage and established Taiwan Residential Earthquake Insurance Pool (TREIP, in short) in April 2002. As of the end of 2004, the participation ratio had risen to 15.44 from $5.99 \%$ of 2002, compared with $15 \%$ of Japan and 25\% in California. Meanwhile, Fig. 1 displays the spatial distribution of the premium for TREIP received during 2002 in the 23 counties and cities of Taiwan. Visual examination reveals that the premiums come mostly from northern Taiwan. In general, seismic risks not being evenly distributed throughout all areas, certain areas are subject to frequent earthquakes while other areas rarely experience them. It is a reasonable to see that when insured take out an earthquake insurance decision, "regional differentiation" may be considered in analyzing insurance demand. It is necessary to incorporate considerations of spatial and regional effects to avoid erroneous conclusion (Lenzi and Millo, 2005). 
In the paper, we make a study on the key issues that "location matters" is at the heart of the current wave of literature about the use spatial methods in applied econometrics. Spatial econometrics could well apply to insurance demand (Anselin, 1988; Lowe, 2004; Lenzi and Millo, 2005). This paper explores a spatial model to investigate the TREIP market and testing whether these observable economic and demographic factors are able to fully account for regional variability in insurance density.

This paper is organized as follows. Section 2 describes the literature review and some theoretical results concerning the estimation of the insurance demands. Section 3 describes the methodology concerning the estimation of the spatial weights and spatial panel regression model. Section 4 we apply our approach to real data and empirical results. General discussion and ideas for future research conclude the paper in Section 5.

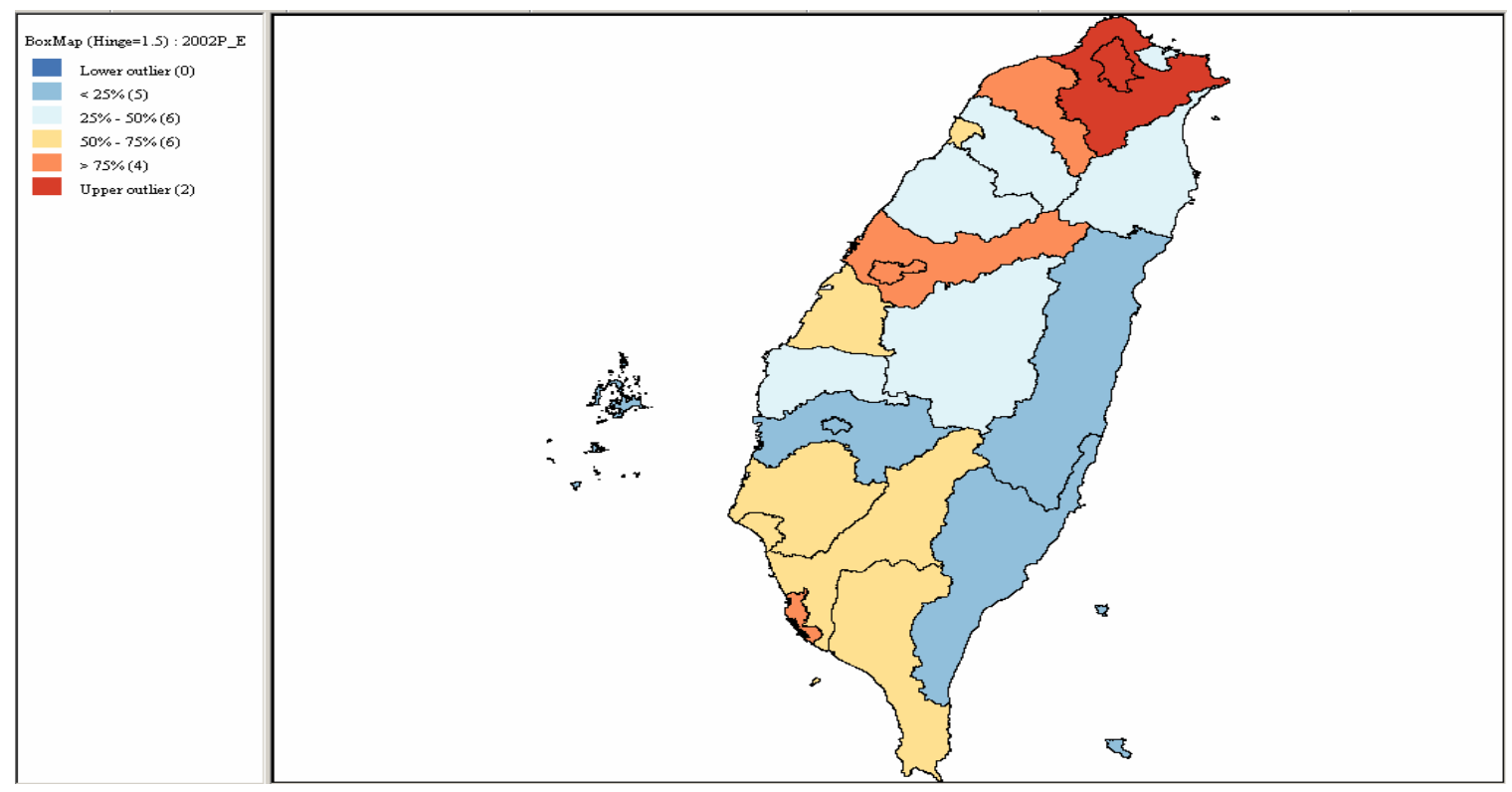

Figure1 Spatial Distribution of Residential Earthquake Insurance Premium in 2002

\section{LITERATURE REVIEW}

The theory underpinning the demand for earthquake insurance has received considerable scholarly attention (Kunreuther and Kleffner,1992; Kunreuther, et al., 1992; Kunreuther, 1996; Yeh, et al., 2006). A disaster-management program which utilizes insurance coupled with well-enforced building codes to reduce future damage and banks and financial institutions play a key role in this program by requiring inspections of homes as a condition for a mortgage (Kunreuther, 1996). The seismic insurance policy 
for residential buildings can be regarded as a tool of catastrophic risk management (Yeh, et al., 2006). A compulsory earthquake insurance scheme has been introduced for all householders in Turkey to transfer of the earthquake risk absorbed by the Turkish Catastrophe Insurance Pool (TCIP, in short) to the international reinsurance market (Bommer, et al., 2002). TCIP to serve as a basis for the decision-making process with respect to the pricing of its insurance policy, risk control, the purchase of reinsurance, and the transfer of seismic risk and to speed up repair and reconstruction in the event of an earthquake, given that the insurance industry has established processes for assessing and dealing with claims which tend to work more efficiently than government compensation schemes (Bommer, et al., 2002). In Taiwan, earthquake coverage becomes a mandatory element of residential fire insurance for newly bought residential properties that are financed through housing loan and then linking Taiwan Residential Earthquake Insurance Pool (TREIP, in short) avoid price fluctuations and stabilize risk transferring costs. Since then, these premiums and funds are put in a TREIP Fund and will be the principal source of relief should there be a large earthquake. If the amount in the fund is insufficient, a pro rata distribution by co-insurers will be made to the insured beneficiaries. The damage relationships obtained with earthquake loss reports from different site conditions, along with exact distribution of damage intensities, local population and personal income. However, the mitigation will be encouraged through low interest state loans as the Fund grows and by reduced premiums to properties that are improved to resist earthquake loss.

From above literatures, this paper aims at assessing the drivers of insurance consumption from regional new perspective and testing whether these observable economic and demographic factors are able to fully account for regional variability in insurance density. The evidence of spatial effects highlights the importance of taking the spatial perspective into account when doing inference on regional data. We can see that general approach applied to investigate insurance demand or consumption differentials largely neglect linkages between neighboring regions. Linkages between regions are considered to some extent since migrations is taken into account. However, corresponding models do not explicitly incorporate a spatial dimension. It is often ignored that migration and other forms of spatial interaction are exposed to the frictional effects of distance. This paper, therefore explores a new spatial perspective to assess the factors that influences the demand of earthquake insurance in Taiwan. 


\section{MODEL AND METHODOLOGY}

This paper aims at assessing the drivers of insurance consumption and investigating the significance of spatial interaction for regional insurance demand disparities in TREIP. Due to lack interregional commuting, trade, and migration data, the spatial dimension of residential earthquake insurance market is investigated by measures of spatial autocorrelation and spatial panel regression model.

\section{Specification of Spatial Weights}

Measures of spatial autocorrelation takes into account the various directions of dependence by a spatial weights matrix $\mathrm{W}$. For a set of $\mathrm{n}$ observations, the matrix $\mathrm{W}$ is a nxn matrix the diagonal elements of which are set to zero. The matrix specifies the structure and intensity of spatial effects. Hence, the element Wij represents the intensity of effects between two regions $i$ and $j$. A frequently applied weight specification is a binary spatial weight matrix such that $W i j=1$ if the regions $i$ and $j$ share a border and $\mathrm{Wij}=0$ otherwise.

$$
W=\left\lfloor W_{i j}\right\rfloor_{n \times n}
$$

\section{Spatial Autocorrelation}

Currently, various indexes are used for measuring "spatial autocorrelation", such as joint count, Moran's I, Geary's and Global G, etc., where "Moran's I" is the one most frequently used. The computed formula of Moran's I (Moran, 1948) is :

$$
I=\frac{n \sum_{i=1}^{n} \sum_{j=1}^{n} w_{i j}\left(x_{i}-\bar{x}\right)\left(x_{j}-\bar{x}\right)}{\sum_{i=1}^{n} \sum_{j=1}^{n} w_{i j} \sum_{i=1}^{n}\left(x_{i}-\bar{x}\right)^{2}}
$$

Where is the variable value of spatial unit $i$. Wij is the coefficient of the adjacent spatial unit, is the number of spatial unit.

\section{Spatial Panel Regression Model}

A general form of spatial autoregressive or dependence model has been introduced to model cross-sectional spatial data by Anselin (1988). Besides, the diagnostics for spatial dependence can test by through Moran's I error or Likelihood Ratio test. The diagnostics for spatial heteroskedasticity can test by through Breusch-Pagan test. While 
spatial heteroskedasticity could be explained by spatial expansion model (Casetti, 1972) or geographically weighted regression (LeSage, 1999; Fotheringham et al., 2002).

The administrative boundaries have 23 countries/cities in Taiwan. It is not sufficient to statistic power in spatial econometrics. This empirical is estimated over 23 administrative boundaries for the period 2002 to 2004 panel data, therefore. Empirical model in this paper focuses on first-order serial and spatial autoregressive model with spatial and time period fixed effects (LeSage, 1999; Elhorst, 2005). The model is considered in vector form for a cross section of observations at time $\mathrm{t}$.

$$
\begin{aligned}
& Y_{t}=\rho W Y_{t}+\beta X_{t}+\mu+\lambda_{t} e_{N}+V_{t} \\
& V_{i t} \sim N\left(0, \sigma^{2} I_{n}\right)
\end{aligned}
$$

Where $Y_{t}$ denotes a $n x l$ vector consisting of one observation for every spatial unit $(i=1 \ldots \ldots N)$ of the dependent variable in the the time period $(t=1 \ldots T) . X_{t}$ denotes a $\mathrm{n} x k$ matrix of the independent variables. $W$ represents an $N x N$ non-negative spatial weight matrix with zeros on the diagonal describing the spatial arrangement of the spatial units. A vector or matrix pri-multiplied by $\mathrm{W}$ denotes its spatially lagged value. The scalar $\rho$, and the vectors $\beta$ represent the response parameters of the model. The disturbance term consists of $\mu=\left(\mu_{1}, \ldots \ldots \mu_{n}\right)^{\prime}, \lambda_{t} e_{N}$ and $V_{t}=\left(V_{1 t}, \ldots . . V_{N t}\right)^{\prime}$, where $\mu_{i}$ denotes a spatial-specific effect, $\lambda_{t}$ denotes a time-specific effect, which is multiplied with a $N x 1$ vector of unit elements, and $V_{i t}$ are independently and identically distributed error terms for all $\mathrm{i}$ and $\mathrm{t}$ with zero mean and variance $\sigma^{2}$.

The hypothesis of the study is tested with equations of the general form (4), and all variables have been log-transformed in order to remove heteroskedasticity:

$$
\log (I D)_{i t}=\rho W(I D)_{i t}+\beta_{1} \log (P D I)_{i t}+\beta_{2} \log (G S L)_{i t}+\mu_{i}+\lambda_{t}+V_{i t}
$$

As the data are both cross sectional and time series in nature, we estimate equation (4) as a spatial panel regression model. When an observation is from a particular country or city, indicated in the model by the subscript $i$, and an observation is from a particular year, indicated in the model by the subscript $t$. The model is estimated using (I) no fixed effect model, (II) spatial fixed effect model and (III) time fixed effect model in order to control for variation in the dependent variable that is not accounted for by the other independent variables in the model and is due to differences between the states and the years. 


\section{EMPIRICAL RESULTS}

\section{Empirical Proxy and Sample Profile}

Two common normalized insurance consumption measurements are used in the literature as well as among practitioners: Insurance penetration, defined as the ratio of insurance premiums on GDP, measures the importance of the insurance sector with respect to the total economy. Insurance density, defined as premiums per capita, measures average per capita expenditure. Being insurance density is better explained than insurance penetrations in developing countries (Meng, 1994), this empirical model is estimated using insurance density.

In Taiwan, earthquake coverage becomes a mandatory element of residential fire insurance for newly bought residential properties that are financed through housing loan. The annual premium is a flat NT\$1,459 for each household, applicable to the whole country. Though price is an important factor in the demand theory, it is not included in the model specification. Therefore, we have been based on the hypothesis that the density of the earthquake insurance is a function of income and policy feature. The proxy we use for income is personal disposable income, and government subsidized loan of the respective area for policy feature.

Due to limited of sample sources consist of only 23 counties/cities in Taiwan, as for the empirical data, This paper plan to use the 2002-2004 annual data of the insurance density, the disposable income, the numbers of government subsidized loan for residential in the counties/cities of Taiwan (with the exceptions of Kinmen and Mazu). The data of insurance density is obtained and computed from statistics for residential earthquake insurance by city/county in annual statistics for fire insurance, R.O.C., 2004. The other variables including personal disposal income and government subsidized loan are obtained form directorate-general of budget, accounting and statistics (http//:www.dgbas.gov.tw), executive Yuan, R.O.C. In Table1, we give a description of these variables and hypothesis. 
Table 1 Descriptive Statistics for Variables

\begin{tabular}{|c|c|c|c|c|}
\hline Variable & Definition & Mean & Std Dev. & Hypothesis \\
\hline 2002ID & $\begin{array}{l}\text { Premium per capita } \\
\text { In NT dollars in } 2002\end{array}$ & 25.15 & 9.89 & \\
\hline 2003ID & $\begin{array}{l}\text { Premium per capita } \\
\text { In NT dollars in } 2003\end{array}$ & 51.89 & 29.70 & \\
\hline 2004ID & $\begin{array}{l}\text { Premium per capita } \\
\text { In NT dollars in } 2004\end{array}$ & 71.34 & 40.34 & \\
\hline 2002PDI & $\begin{array}{l}\text { Disposable personal income } \\
\text { per capita in NT dolls in } 2002\end{array}$ & 221692.29 & 39581.61 & + \\
\hline 2003PDI & $\begin{array}{l}\text { Disposable personal income } \\
\text { per capita in NT dolls in } 2003\end{array}$ & 230118.71 & 41831.41 & + \\
\hline 2004PDI & $\begin{array}{l}\text { Disposable personal income } \\
\text { per capita in NT dolls in } 2004\end{array}$ & 237465.28 & 43882.53 & + \\
\hline $2002 \mathrm{GSL}$ & $\begin{array}{l}\text { Government subsidized loan } \\
\text { per countries/cities in } 2002\end{array}$ & 1498 & 3991 & + \\
\hline 2003GSL & $\begin{array}{l}\text { Government subsidized loan } \\
\text { per countries/cities in } 2003\end{array}$ & 930 & 2294 & + \\
\hline 2004GSL & $\begin{array}{l}\text { Government subsidized loan } \\
\text { per countries/cities in } 2004\end{array}$ & 351 & 705 & + \\
\hline
\end{tabular}

Note: ID: Insurance Density; PDI: Personal Disposal Income; GSL: Government Subsidized Loan.

From Spatial autocorrelation results, we can see that figure 2 is the Moran plot of insurance density, shows an evident cluster of low-density regions correlated with their neighbors, and the same applies to most observations. More formal statistical test confirms the visual impression. Table2 shows that Moran's I value and test for spatial autocorrelation among regional insurance demand to $0.362,0.210$, and 0.188 in 2002, 2003, and 2004 respectively. The variable in three years is all significantly to positive correction. 


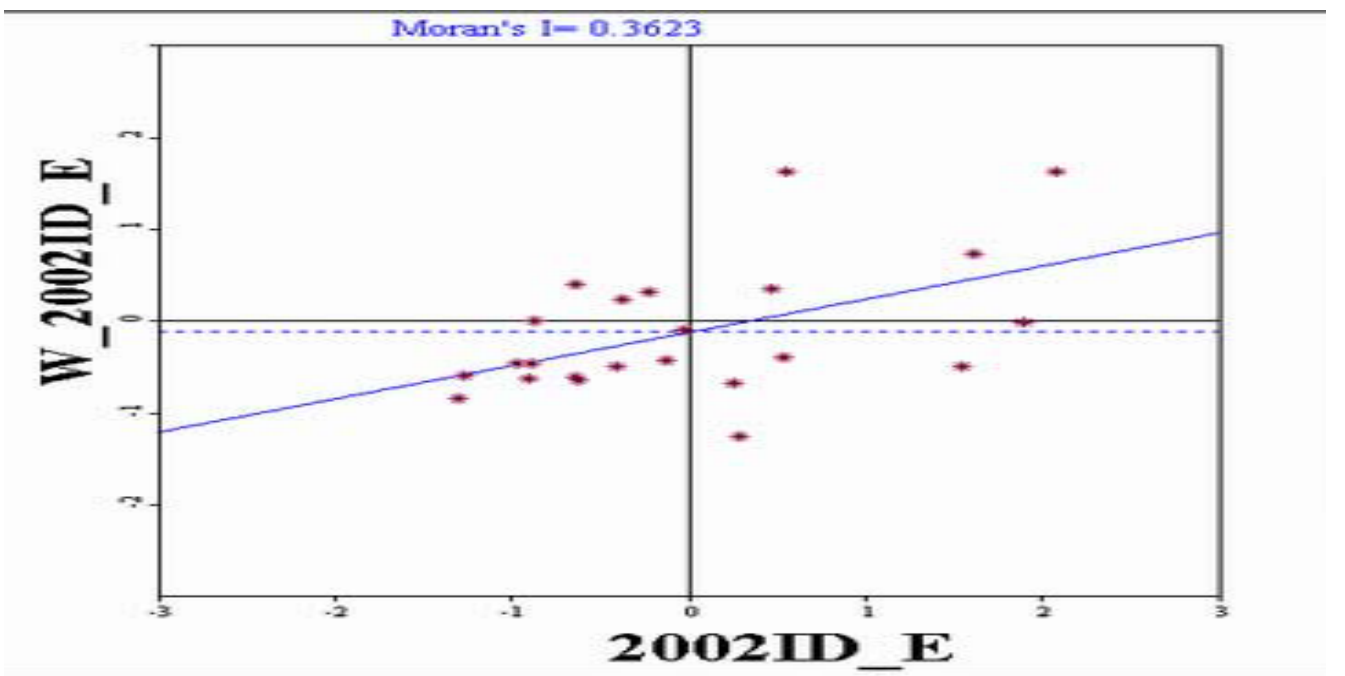

Note: 2002ID_E: Insurance Density of TREIP in 2002.

W_2002ID_E: The coefficient of Wij* Insurance Density of TREIP in 2002.

Fig.2 Moran Plot of Insurance Density in 2002

Table 2 Spatial Dependence Test

\begin{tabular}{|l|c|c|c|}
\hline \multirow{2}{*}{ Variable } & \multicolumn{3}{|c|}{ Insurance Density } \\
\cline { 2 - 4 } & 2002 & 2003 & 2004 \\
\hline Moran's I & 0.362 & 0.2100 & 0.1877 \\
\hline P-value & $0.008^{* * *}$ & $0.0550^{*}$ & $0.0690^{*}$ \\
\hline \multirow{2}{*}{$\mathrm{P}<0.1 . * * \mathrm{P}<0.05 . * * * \mathrm{P}<0.01$} &
\end{tabular}

The empirical analysis reported in Table 3 . Income proxy is positive $(1.716,2.245$, 2.076) and statistically significant in these three models. It is consistent with our hypothesis. Contrary to our hypothesis, this empirical result finds the number of government subsidized loan is negatively related to the demand. While the literature and market practice contend that government subsidized loan will increase the consumption of residential earthquake insurance. The coefficient $(0.229,0.408$, and 0.260$)$ of the current value of spatially lagged dependent variable $\left(\mathrm{W}^{*} \mathrm{Y}\right)$ is substantial and significant. Significant spatial interaction between neighboring countries or cities implies that cross sectional data is marked by a positive spatial autocorrelation. In this case, similar insurance density, either high or low, is more spatially clustered than could be caused by chance.

Table 3 presents the results from estimating the three insurance demand of earthquake using spatial panel regression method. Region, personal disposable income, 
and government subsidized loan have effect on insurance demand of earthquake in Taiwan. The empirical analysis supports the hypothesis that income is influential factor in one's decision to purchase residential earthquake insurance. While government subsidized loan is statistic significant but not consistent to our hypothesis. We find that spatial variable have more effect and explain reliability on making decision to purchase residential earthquake insurance than the results from in traditional model.

Table 3 Estimated Spatial Regression Results, Dependent Variable

\begin{tabular}{|c|c|c|c|c|c|c|}
\hline \multicolumn{6}{|c|}{ Dependent Variable: Residential Earthquake Insurance Demand } \\
\hline & \multicolumn{2}{|c|}{ No Fixed Effect } & \multicolumn{2}{c|}{ Spatial Fixed Effect } & \multicolumn{2}{c|}{ Time Fixed Effect } \\
\hline $\begin{array}{c}\text { Explanatory } \\
\text { variable }\end{array}$ & coefficient & z-prob. & coefficient & z-prob. & coefficient & Z-prob. \\
\hline \hline constant & -7.634 & $0.002^{* * *}$ & & & & \\
LPDI & 1.716 & $0.000^{* * *}$ & 2.245 & $0.020^{* * *}$ & 2.076 & $0.000^{* * *}$ \\
LGSL & -0.131 & $0.006^{* * *}$ & -0.131 & $0.008^{* * *}$ & -0.173 & $0.000^{* * *}$ \\
$\mathrm{~W}_{-2}^{*} \mathrm{Y}$ & 0.229 & $0.001^{* * *}$ & 0.408 & $0.000^{* * *}$ & 0.260 & $0.028^{* * *}$ \\
$R$ & 0.323 & & 0.591 & & 0.264 & \\
Log- & 4.251 & & 34.721 & & 5.184 & \\
likelihood & & & & & \\
\hline
\end{tabular}

$* * * \mathrm{P}<0.01$, Note: LPDI: $\log$ (personal disposal income), LGSL: log (government subsidized loan).

\section{CONCLUSION}

The focus of this research has been on explaining the relations between the factors of earthquake insurance demand. In general approach that applied to investigate demand factors of insurance market largely neglects linkages between neighboring regions. We show that different spatial characteristics in the earthquake insurance market are validated. The results of these empirical studies indicate that government subsidized loan is significantly negative relationship with demand for residential earthquake insurance, which was to the contrary of the hypothesis. In other word, government subsidized loan is statistic significant but not consistent to our hypothesis. We could be referred to as the fact that the government housing loan may not available for purchasing earthquake insurance. Disposal income and spatial variables are significantly positive relationship with demand for residential earthquake insurance, which was to the accord with the hypothesis. Therefore, region has significant effects on the demand for residential 
earthquake insurance in Taiwan, the more improving the ability of explanations can be contributed by the spatial effect model if spatial variable is linked with demand for residential earthquake insurance. The paper provides a scientific basis for fixing rate factors of earthquake insurance under the residential fire insurance and it also provides a useful reference for adjusting coverage of residential earthquake insurance in Taiwan.

\section{REFERENCES}

Anselin, L. (1988). Spatial Econometrics: Methods and Models. Dordrecht/Boston/London: Kluwer Academic Publishers.

Bommer, J., Spence, R., Erdik, M., Tabuchi, S., Aydinoglu, N., Booth, E., Re, D. D., And Pterken, D. (2002). Development of an Earthquake Loss Model for Turkish Catastrophe Insurance. Journal of Seismology, 6, 431-446.

Casetti, E. (1972). Generating Models by the Expansion Method: Applications to Geographical Research. Geographical Analysis, 4, 81-91.

Elhorst, J. P. (2005). Unconditional Maximum Likelihood Estimation of Linear and Loglinear dynamic Models for Spatial Panels. Geographical Analysis, 37, 85-106.

Fortheringham, A. S., Brunsdon, C., and Charlton, M. (2002). Geographically Weighted Regression. UK: John Wiley \& Sons.

Kunreuther, H. (1996). Mitigating Disaster Losses through Insurance. Journal of Risk and Uncertainty, 12, 171-186.

Kunreuther, H., and Kleffner, A. E. (1992). Should Earthquake Mitigation Measures Be Voluntary or Required? Journal of Regulatory Economics, 4, 321-333.

Kunreuther, H., Doherty, N., and Kleffner, A. (1992). How Should Society Deal with the Earthquake Problem? Regulation, Spring, 60-68.

Lenzi, A. and Millo, G. (2005). Regional Heterogeneity and Spatial Spillovers in Italian Insurance Market. Paper presented at the workshop on applied economics of insurance, ROME.

LeSage, J. P. (1999). Applied Econometrics using MATLAB. Available at http://www.spatial-conometrics.com/html/mbook.pdf.

Lowe, J. W. (2004). Spatial Trends and Drivers in Insurance Loss Modeling. Geospatial Solutions, 14, 42-45.

Meng, X. (1994). Insurance Markets in Developing countries: Determinants, Policy implications, and the Case of China. Unpublished doctoral dissertation, University of Temple University, USA. 
Moran, P. (1948). The Interpretation of Statistical Maps. Journal of the Royal Statistical Society, 10, 243-51.

Swiss Re. (2001). Natural Catastrophes and Man-made Disasters in 2000, Sigma, 2.

Yeh, C. H., Loh, C. H., and Tsai, K. C. (2006). Overview of Taiwan Earthquake Loss Estimation System. Natural Hazards, 37, 23-37. 